\title{
Self-Reported Compliance with Personal Preventive Measures among Office Workers After Work Resumption during the COVID-19 Outbreak in Pakistan
}

\author{
Pankaj Kumar, ${ }^{1}$ Aruba Sohail, ${ }^{1}$ Mir Umer Farooq Alam Shah, ${ }^{1}$ Maman Khurshid, ${ }^{1}$ Farah Yasmin, ${ }^{1}$ and \\ Muhammad Sohaib Asghar ${ }^{2 *}$ \\ ${ }^{1}$ Department of Internal Medicine, Dow University of Health Sciences, Karachi, Pakistan; ${ }^{2}$ Department of Internal Medicine, Dow University of \\ Health Sciences-Ojha Campus, Karachi, Pakistan
}

\begin{abstract}
As the lockdowns have been lifted to relieve pressure on the economy, strict adherence to personal preventive measures (PPMs) in offices is essential to control the COVID-19 pandemic. This study investigated self-reported compliance with three PPMs among a sample of office workers in Karachi, Pakistan. A cross-sectional survey with participants were adult office workers who had resumed work in Karachi, Pakistan. All full-time employees aged $\geq 18$ years who had resumed work in the offices were invited to complete the survey. Of 487 workers who were invited, 411 (84.4\%) completed the survey between March 1 and March 20, 2021. We examined the effects of sociodemographic factors, individual-level factors, interpersonal-level factors, and social-structural-level factors using logistic regression models. Of the total sample, $192(46.7 \%)$ reported always wearing a face mask in the workplace. Self-reported sanitizing of hands $(46.0 \%)$ was comparable to use of face masks, whereas avoiding crowded places $(21.2 \%)$ was less common. Perceived effectiveness of individual preventive measures (adjusted odds ratios [AORs] from 1.19 to 1.42; confidence intervals (Cls) 1.04-1.37 to $\mathrm{Cl} 1.18-1.71$ ), perceived effectiveness of governmental preventive measures (AORs from 1.23 to $1.39 \mathrm{Cl}$ $1.02-1.47$ to $\mathrm{Cl} 1.12-1.72$ ), and number of preventive measures implemented by the office (AORs from 1.20 to $1.26 \mathrm{Cl}$ 1.09-1.31 to $\mathrm{Cl} 1.13-1.39)$ were associated with self-reported compliance with PPMs. Perceived preparedness of medical system in Karachi (AOR 1.44, Cl 1.08-1.93) was only associated with self-reported sanitizing of hands. Reduced compliance to PPMs was observed; hence, efforts need to be made to ensure strict adherence to PPMs.
\end{abstract}

\section{INTRODUCTION}

As of April 28, 2021, 149,368,127 cases of COVID-19 and $3,149,698$ deaths from the disease have been reported worldwide. $^{1}$ Pakistan has reported 810,231 confirmed COVID-19 cases and 17,530 deaths. ${ }^{1}$ Initially a nationwide lockdown was imposed by the government to curb the spread of the virus. However, such restrictions adversely affected the country's economy. Pakistan, being a low- to middle-income country, could not afford extended periods of lockdown. Hence, the government of Pakistan decided to relax the lockdown in phases. ${ }^{2}$ The government released strict guidelines and standard operating procedure documents to ensure safe resumption of work in offices. According to the $\mathrm{WHO}$, indoor locations, especially settings that are enclosed and confined with poor or no ventilation, are riskier than outdoor locations. ${ }^{3}$ Also, people can be in close proximity to each other for long hours in offices. This makes it essential to ensure compliance to personal preventive measures (PPMs) in offices to reduce the risk of contraction.

The WHO released guidelines suggesting the use of face masks, hand hygiene, and physical distancing as PPMs against the virus. ${ }^{4}$ Studies from China ${ }^{5}$ and Australia ${ }^{6}$ reported that a high compliance (80-95\%) with PPMs played a pivotal role in curtailing the spread of the virus in these countries. If strict compliance with preventive measures is maintained in offices and other businesses, Pakistan would be able to keep its fragile economy operational amid the pandemic. However, the compliance with PPMs is dependent on many factors. Investigating those factors is important in ensuring an effective infection control. In southern Ethiopia,

*Address correspondence to Muhammad Sohaib Asghar, Dow University of Health Sciences, B328 Block 6 Gulshan E Iqbal, Karachi, Pakistan 73500. E-mail: sohaib_asghar123@yahoo.com good knowledge was observed to be a significant factor associated with the participants' actual practice of the PPMs. ${ }^{7}$ In Lebanon, COVID-19 related news increased knowledge and inculcated fear which ultimately led to increased compliance with ppms. ${ }^{8}$ An international study stated that women were somewhat more likely to engage in these health behaviors than men, but age was unrelated to voluntary compliance behaviors. ${ }^{9}$ Lastly, in Australia, avoidance-related behaviors (avoiding crowds, public transport, and complying with quarantine restrictions) were associated with trust in government/authorities and higher perceived rating of effectiveness of behaviors. ${ }^{10}$ At the social-structural level, implementation of organizational preventive measures during work resumption may differ across offices, which may also affect compliance with personal preventive measures.

To the best of our knowledge, no study has investigated self-reported compliance with personal preventive measures and associated factors among workers who resumed work during the COVID-19 pandemic in Karachi, Pakistan. This study examines the effects of sociodemographic factors, individual-level factors (knowledge and perception), interpersonal-level factors (exposure to COVID-19-specific information through different media), and social-structural-level factors (preventive measures implemented by the offices) on compliance to three personal preventive measures among a sample of office workers in Karachi, Pakistan.

\section{METHODS}

Study design and sample size. We conducted a crosssectional survey of employees who had resumed work in offices during the COVID-19 pandemic in Karachi, Pakistan, between March 1, 2021 and March 20, 2021. The restrictions were eased in phases from May 9, 2020, hence the study was conducted almost a year following the initial lifting of 
lockdown. We approached eight offices, which included pharmaceutical companies, advertising companies, insurance companies, and banks. Pharmaceutical companies belonged to the health industry. We used OpenEpi: Open Source Epidemiologic Statistics for Public Health to calculate sample size by following single population proportion assumptions of $95 \%$ confidence level $(\mathrm{Cl})$, expected prevalence of intention to practice PPMs of $50 \%$, and $5 \%$ degree of precision. ${ }^{11}$ The sample size calculated using these assumptions was 384 . The questionnaire was sent to 487 employees to account for nonrespondents so that the required sample size could be met. Ethical approval was obtained from institutional review board of Dow University Hospital. We received responses from 411 employees, resulting in a positive response rate of $84.4 \%$. Almost half of these responses came from those used in advertising companies $(49.6 \%)$, followed by bankers $(25.2 \%)$, pharmaceutical companies (13.3\%), and insurance staff (11.9\%). Finally, response from 411 office workers was recorded.

Participants and data collection. Since the restrictions were relaxed, many offices in Karachi had resumed work. Full-time employees aged $\geq 18$ years who had resumed work in offices were invited to complete the survey. Parttime employees and employees working from home were excluded from the study.

A web-based questionnaire was developed using Google forms. The members of the research team visited many offices that had resumed work during the pandemic. After taking permission from the administration, the link to the questionnaire was disseminated among the employees using e-mail. Hardcopies of the questionnaire were also distributed among those employees who did not have access to electronic devices or the internet. Some of the employees were also approached through Linkedln and other professional networking websites. The link to the questionnaire was sent only after assessing whether the employees fit the inclusion criteria or not. Reminders were also sent after every 3 days to ensure the completion of the survey by the participants. Web-based informed consent was obtained. The participation of the volunteers was entirely voluntary. The survey contained 39 items and required approximately 5 minutes to complete. Google form performed completeness checks before the questionnaire was submitted. Only the corresponding authors had access to the data collected and anonymity of responses was ensured at all stages of study.

Measures. Design of the questionnaire. The questionnaire was adapted from the WHO Survey tool and Guidance on COVID-19 and literature related to our study. ${ }^{12,13}$ The questionnaire was made in both English and the native language Urdu to ensure that all the items were understandable to the participants. The questionnaire was pilot-tested among eight office workers to assess its clarity. These workers did not participate in the actual survey. Based on the participants' comments, the questionnaire was revised and all the ambiguities were removed.

Self-reported compliance with PPMs in the past month. Participants were asked to report the frequency at which they wore face masks in their offices, and in other public settings apart from their workplaces (public transport) in the past month (response categories: every time, often, sometimes, never). A new variable was created that was termed as "consistent wearing of facemasks in any public place."
This composite variable referred to the participants who reported always using a face mask both in the workplace and other public settings such as public transport. The participants were also asked about the type of face mask they used and whether they reused their face masks. The participants also reported the frequency at which they sanitized their hands using soaps, liquid soaps, and alcohol-based sanitizers after returning from public places or touching public installations, and whether they avoided crowded places or not (response categories: every time, often, sometimes, never).

Background characteristics. Participants were asked to report sociodemographic characteristics such as gender, age, marital status, highest education level attained, and designation in the office.

Individual-level variables. To determine the participants' knowledge related to transmission routes of COVID-19, a composite indicator variable was constructed by counting the number of correct responses to five knowledge items related to COVID-19 transmission routes (ranging from 0 to 5). To assess their perceptions related to COVID-19, three scales were constructed for this study: 1) the four-item Perceived Severity Scale, 2) the four-item Perceived Effectiveness of Individual Preventive Measures Scale, and 3) the 2-item Perceived Effectiveness of Governmental Preventive Measures Scale. The response categories for these scales were 1 = disagree/ineffective, $2=$ neutral, and $3=$ agree/effective. The Cronbach alpha values of all three scales were $>0.7$, and single factors were identified by exploratory factor analysis that cumulatively explained $61.6 \%$ of the total variance. A single item was used to measure the perceived preparedness of the medical system of Karachi with the same response categories as the scales. In addition, a single item was used to measure the participants' perceived risk of contracting COVID-19 in the next 3 months (response categories: $1=$ low, 2 = moderate, $3=$ high), and another item measured the perceived effectiveness of preventive measures implemented by the offices (response categories: $1=$ very ineffective, 2 = ineffective, 3 = neutral, 4 = effective, 5 = very effective).

Interpersonal-level variables. A single item was used to assess the daily average time (hours) of exposure to COVID19-specific information through TV, newspaper, social media, and interpersonal communication. The response categories for the aforementioned items were $1=$ almost none, $2=$ less than 1 hour, $3=1-2$ hours, $4=3-4$ hours, and $5 \geq 4$ hours.

Social-structural-level variables. The study participants were asked to report whether their offices had implemented the nine preventive measures to allow safe resumption of work in the offices. A composite indicator variable was also created by counting the number of preventive measures implemented by the office (ranging from 0 to 9).

Statistical analysis. The dependent variables were selfreported consistent wearing of a face mask in public spaces, sanitizing hands every time after returning from public spaces or touching public installations, and always avoiding crowded places. Logistic regression models were chosen to analyze the factors associated with dependent variables. Univariate logistic regression was used to assess the significance of the association between each of the background characteristics and the dependent variables. Statistical Package for the Social Sciences (SPSS) version 23.0 for Windows (IBM Corporation) was used for data analysis and $P \leq 0.05$ was considered statistically significant. 


\section{RESULTS}

Background characteristics. We approached 487 office employees who had resumed work during the pandemic to fill the survey, and 411 of them completed the survey, for an overall response rate of $84.4 \%$. Nearly three-quarters $(72.3 \%)$, of the employees were aged $>30$, married $(74.2 \%)$ and appointed at high-ranking positions in their offices $(72.5 \%)$. The majority were men $(86.1 \%)$ and had completed tertiary education $(91.7 \%)$ (Table 1$)$.

Self-reported compliance with PPMs in the past month. In the past month, 192 participants (46.7\%) reported always wearing facemasks in the workplace, and 228 participants $(55.5 \%)$ reported always wearing a face mask in other public settings. One hundred twenty-seven (30.9\%) participants reported "consistently wearing a face mask in any public place." Surgical masks were the choice of $77.9 \%$ of the participants, and $64.2 \%$ of the participants reused their face masks. Self-reported sanitizing of hands $(46.0 \%)$ was comparable to compliance with the use of face masks, whereas avoiding crowded places (21.2\%). Tables 2 and 3 show the responses to the survey items measuring the individual and interpersonal variables, and Table 4 reports the responses to social-structural-level variables.

Factors associated with self-reported compliance with PPMs in the past month. In the univariate logistic regression analysis, age, gender, education level, and job position were significantly associated with self-reported compliance with one or more PPMs. The odds of wearing a face mask consistently in public place were 2.3 times higher in females (odds ratio [OR] 2.29, 95\% confidence interval [Cl] 1.29-4.04; $P=0.004$ ) compared with males. The odds of sanitizing hands were significantly higher for those who received tertiary education (college/university and postgraduate) compared with those who have only done intermediate or matriculation. People aged 26 to 40 years had a significantly higher odds of compliance toward consistent hand sanitizing in the workplace. Lower job ranks were

TABLE 1

Background characteristics of participants $(N=411)$

\begin{tabular}{lr}
\hline \multicolumn{1}{c}{ Characteristics } & Value (\%) \\
\hline Age (years) & $47(11.4)$ \\
$18-25$ & $67(16.3)$ \\
$26-30$ & $152(37.0)$ \\
$31-40$ & $145(35.3)$ \\
$>40$ & \\
Gender & $354(86.1)$ \\
Male & $57(13.9)$ \\
Female & \\
Relationship status & $305(74.2)$ \\
Married & $106(25.8)$ \\
Unmarried & $234(56.9)$ \\
Highest level of education attained & $143(34.8)$ \\
Postgraduate & $23(5.6)$ \\
College/university & $11(2.7)$ \\
Intermediate & $125(30.4)$ \\
Matriculation & $173(42.1)$ \\
Occupational position & $73(17.8)$ \\
Chief operating officer/director/ & $23(5.6)$ \\
$\quad$ general manager (heads) & $17(4.1)$ \\
Managers & \\
Officers & \\
Cleaning staff/receptionist & \\
Others & \\
\hline
\end{tabular}

TABLE 2

Self-reported compliance with personal protective measures related to COVID-19 $(N=411)$

\begin{tabular}{|c|c|}
\hline Measures and responses & $N=411(\%)$ \\
\hline \multicolumn{2}{|c|}{ Frequency of face mask wearing in the workplace } \\
\hline Every time & $192(46.7)$ \\
\hline Often & $148(36.0)$ \\
\hline Sometimes & 67 (16.3) \\
\hline Never & $4(1.0)$ \\
\hline \multicolumn{2}{|c|}{ Frequency of facemask wearing in public places } \\
\hline \multicolumn{2}{|c|}{ except workplace (e.g., public transportation) } \\
\hline Every time & $228(55.5)$ \\
\hline Often & $122(29.7)$ \\
\hline Sometimes & $53(12.9)$ \\
\hline Never & $8(1.9)$ \\
\hline \multicolumn{2}{|c|}{ Consistent wearing of face mask in any public place } \\
\hline Yes & $127(30.9)$ \\
\hline No & $284(69.1)$ \\
\hline \multicolumn{2}{|l|}{ Type of face mask worn } \\
\hline Surgical mask & $320(77.9)$ \\
\hline Cloth mask & 49 (11.9) \\
\hline N-95 mask & $42(10.2)$ \\
\hline \multicolumn{2}{|l|}{ Reuse of face mask } \\
\hline No & $147(35.8)$ \\
\hline Yes & $264(64.2)$ \\
\hline \multirow{2}{*}{\multicolumn{2}{|c|}{$\begin{array}{l}\text { Frequency of hand sanitization (using soap, liquid } \\
\text { soap or alcohol-based sanitizer) after } \\
\text { returning from public spaces or touching } \\
\text { public installations }\end{array}$}} \\
\hline & \\
\hline Every time & $189(46.0)$ \\
\hline Often & $155(37.7)$ \\
\hline Sometimes & $64(15.6)$ \\
\hline Never & $3(7.0)$ \\
\hline \multicolumn{2}{|l|}{ Avoiding crowded places } \\
\hline Always & $87(21.2)$ \\
\hline Often & $228(55.5)$ \\
\hline Sometimes & $87(21.2)$ \\
\hline Never & 9 (2.2) \\
\hline
\end{tabular}

significantly associated with reduced odds of avoiding crowds compared with heads of the organizations as shown in Table 5.

After adjusting for these significant background characteristics; perceived effectiveness of individual preventive measures, governmental preventive measures, and number of preventive measures implemented by the office were significantly associated with consistent usage of facemask in any public place, and sanitizing hands every time after returning from public places with the exception of avoiding crowds. Perceived preparedness of medical system in Karachi (adjusted OR 1.44, 95\% Cl: 1.08-1.93; $P=0.01$ ) was only associated with self-reported sanitizing of hands but not with other personal preventive measures as shown in Table 6.

\section{DISCUSSION}

On March 11, 2020, that COVID-19 was declared a pandemic by the $\mathrm{WHO}^{14}$ Lockdowns and restrictions were imposed worldwide to curtail the spread of the virus. Even after almost a year, on February 25, 2021, 430,167 confirmed cases and 10,714 deaths were reported worldwide, ${ }^{15}$ although many countries had started rolling out vaccines. Because countries, especially low- to middle-income countries, cannot afford extended periods of lockdown due to detrimental effects on the economy; compliance to personal preventive measures is necessary in workplaces and public 
TABLE 3

Responses to survey items measuring individual-level variables $(\mathrm{N}=411)$

\begin{tabular}{|c|c|}
\hline Variable & Value \\
\hline Daily average time to COVID-19-related information through different official media channels (answered $>1$ hour), $n$ (\%) & $195(47.4)$ \\
\hline Daily average time to COVID-19-related information through different official media channels, mean (SD) & $2.17(2.5)$ \\
\hline \multicolumn{2}{|l|}{ Knowledge about route of transmission of COVID-19 (answered yes), $n(\%)$} \\
\hline Contact with droplets & $336(81.8)$ \\
\hline Touching contaminated objects & $344(83.7)$ \\
\hline Direct contact with wildlife & $53(12.9)$ \\
\hline Contact with feces & $66(16.1)$ \\
\hline Contact with asymptomatic patients & $247(60.1)$ \\
\hline \multicolumn{2}{|l|}{ Correct responses to COVID-19 transmission route questions } \\
\hline Number of correct responses, mean (SD) & $3.42(1.1)$ \\
\hline 0 correct response, $\mathrm{n}(\%)$ & $4(1.0)$ \\
\hline 1 correct response, $\mathrm{n}(\%)$ & $17(4.1)$ \\
\hline 2 correct responses, n (\%) & $60(14.6)$ \\
\hline 3 correct responses, $\mathrm{n}(\%)$ & $119(29.0)$ \\
\hline 4 correct responses, $\mathrm{n}(\%)$ & $144(35.0)$ \\
\hline 5 correct responses, $\mathrm{n}(\%)$ & $67(16.3)$ \\
\hline \multicolumn{2}{|l|}{ Perceptions related to COVID-19 } \\
\hline Perceived risk of contracting COVID-19 (answered high), $\mathrm{n}(\%)$ & $48(11.7)$ \\
\hline Perceived risk of contracting COVID-19, mean (SD) & $2.3(0.7)$ \\
\hline \multicolumn{2}{|l|}{ Perceived consequences of COVID-19 (answered agree), n (\%) } \\
\hline Permanent bodily damage to infected people & $131(31.9)$ \\
\hline High mortality rate of infected people & $121(29.4)$ \\
\hline Lack of effective treatment & $247(60.1)$ \\
\hline Lack of effective vaccines for prevention & $306(74.5)$ \\
\hline Perceived Severity Scale score, mean (SD) & $9.0(1.7)$ \\
\hline \multicolumn{2}{|l|}{ Perceived effectiveness of individual-level preventive measures (answered effective), N (\%) } \\
\hline Wearing face masks & $371(90.3)$ \\
\hline Sanitizing hands frequently & $378(92.0)$ \\
\hline Household disinfection & $285(69.3)$ \\
\hline Avoiding gatherings & $350(85.2)$ \\
\hline Perceived effectiveness of Individual Preventive Measures Scale score, mean (SD) & $11.1(1.6)$ \\
\hline Perceived effectiveness of preventive measures taken by the office, (answered effective or very effective), N (\%) & $245(59.6)$ \\
\hline Perceived effectiveness of preventive measures taken by the office, mean score (SD) & $3.4(1.2)$ \\
\hline \multicolumn{2}{|l|}{ Perceived effectiveness of governmental preventive measures (answered effective), $\mathrm{N}(\%)$} \\
\hline Closure of public spaces (e.g., restaurants, theatres etc.) & $239(58.2)$ \\
\hline Smart lockdowns & $282(68.6)$ \\
\hline Perceived effectiveness of governmental preventive measures scale score, mean (SD) & $5.0(1.1)$ \\
\hline \multicolumn{2}{|l|}{ Perceived organizational preparedness for COVID-19 outbreak after work resumption (answered agree), m (\%) } \\
\hline The medical system in Karachi is well prepared for a COVID-19 outbreak after work resumption & $54(13.1)$ \\
\hline Perceived preparedness scale score, mean (SD) & $1.5(0.7)$ \\
\hline
\end{tabular}

places to control the pandemic. However, in our study less than one-third $(30.9 \%)$ of office workers reported consistent use of facemasks in any public place. Only $46 \%$ and $21.2 \%$ of the office workers reported that they sanitized their hands every time and always avoided crowds, respectively. These findings are troublesome because Pakistan is still reporting new confirmed cases and deaths. For example, on February 24, 2021, alone, Pakistan reported 1,361 confirmed cases and 64 deaths from COVID-19 infection. ${ }^{16}$ The vaccines are currently being dispensed among healthcare workers and senior citizens. Hence, it would require a considerable amount of time before the vaccine is accessible to majority of the population and its acceptance increases. Until then, it is important to maintain strict compliance to PPMs.

Pakistan has reported fewer COVID-19 cases and deaths compared with many other countries. As of February 21, 2021, the United States had reported 27,702,074 cases and 491,894 deaths; Iran had reported 1,566,081 cases and 59,409 deaths; and the United Kingdom had reported $4,105,679$ cases and 120,365 deaths; in contrast, Pakistan

TABLE 4

Response to items measuring social-structural level variables $(N=411)$

Taking body temperature and requiring hand sanitation for all employees entering the workplace $335(81.5)$

Providing face masks to all employees

Requiring employees to wear face masks in the workplace

Frequent workplace disinfection

$335(81.5)$

Practicing social distancing in workplace

$277(67.4)$

Random testing of employees

Employees are called to the office on alternate days

$240(58.4)$

$163(39.7)$

Leaves granted to COVID-19-infected individuals

$216(52.6)$

Mandatory 14-day quarantine for employees physically interacting with COVID-19 positive people 
KUMAR AND OTHERS

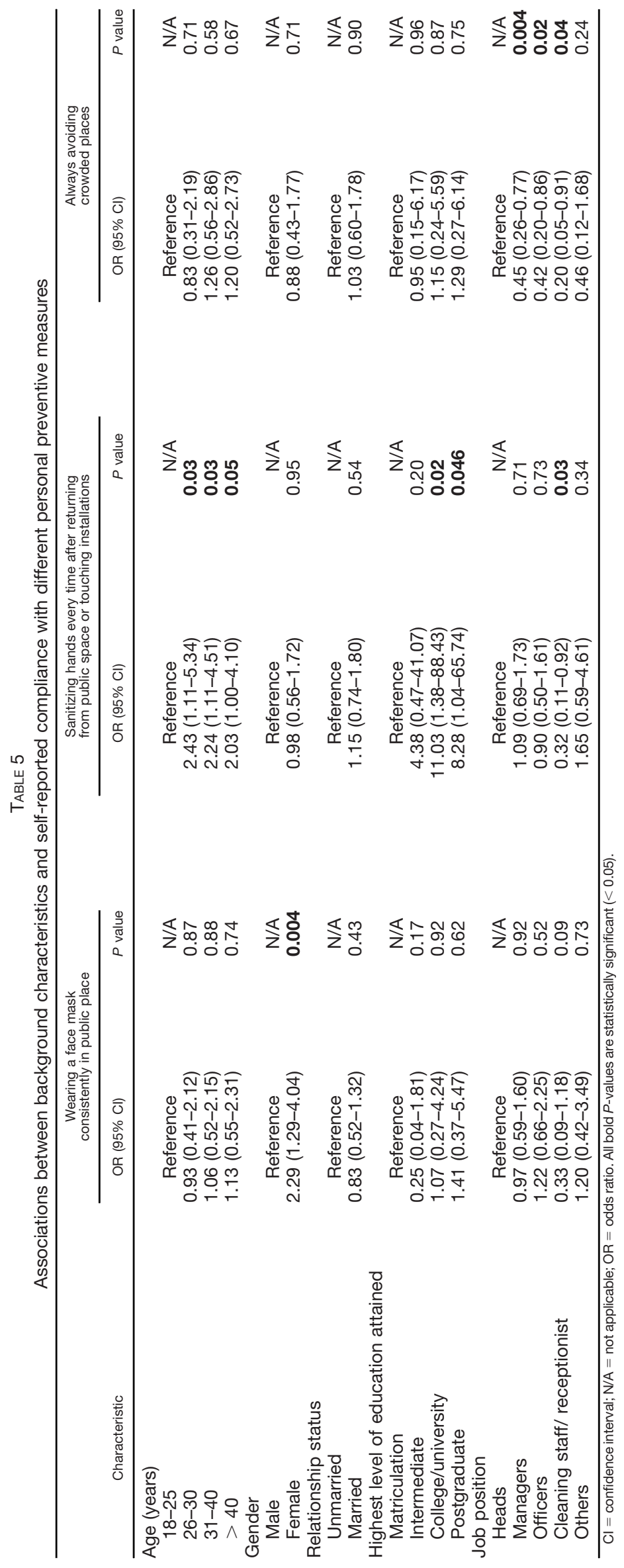


TABLE 6

Factors associated with self-reported compliance with different personal preventive measures

\begin{tabular}{|c|c|c|c|c|c|c|}
\hline \multirow[b]{2}{*}{ Factor } & \multicolumn{2}{|c|}{$\begin{array}{l}\text { Consistent wearing of face } \\
\text { mask in any public place }\end{array}$} & \multicolumn{2}{|c|}{$\begin{array}{l}\text { Sanitizing hands every } \\
\text { time after returning from public } \\
\text { spaces or touching installations }\end{array}$} & \multicolumn{2}{|c|}{$\begin{array}{l}\text { Always avoiding } \\
\text { crowded places }\end{array}$} \\
\hline & AOR $(95 \% \mathrm{Cl})$ & $P$ value & AOR $(95 \% \mathrm{Cl})$ & $P$ value & AOR $(95 \% \mathrm{Cl})$ & $P$ value \\
\hline \multicolumn{7}{|l|}{ Individual-level variables } \\
\hline Exposure to COVID-19 related information & $1.02(0.87-1.19)$ & 0.85 & $1.02(0.88-1.19)$ & 0.75 & $1.05(0.88-1.26)$ & 0.59 \\
\hline \multicolumn{7}{|l|}{ Knowledge and perception } \\
\hline $\begin{array}{l}\text { Knowledge about transmission routes of } \\
\text { COVID-19 }\end{array}$ & $1.13(0.93-1.37)$ & 0.21 & $1.01(0.84-1.22)$ & 0.91 & $0.97(0.78-1.22)$ & 0.81 \\
\hline Perceived risk of contracting COVID-19 & $1.06(0.77-1.45)$ & 0.72 & $1.03(0.77-1.40)$ & 0.83 & $0.99(0.69-1.43)$ & 0.96 \\
\hline Perceived severity of COVID-19 & $1.01(0.89-1.14)$ & 0.89 & $1.11(0.99-1.25)$ & 0.066 & $1.09(0.95-1.25)$ & 0.22 \\
\hline $\begin{array}{l}\text { Perceived effectiveness of individual preventive } \\
\text { measure }\end{array}$ & $1.42(1.18-1.71)$ & $<0.001$ & $1.19(1.04-1.37)$ & 0.01 & $1.06(0.90-1.24)$ & 0.52 \\
\hline $\begin{array}{l}\text { Perceived effectiveness of preventive } \\
\text { measures taken by office }\end{array}$ & $1.14(0.96-1.36)$ & 0.15 & $1.16(0.98-1.36)$ & 0.08 & $1.07(0.88-1.31)$ & 0.50 \\
\hline $\begin{array}{l}\text { Perceived effectiveness of governmental } \\
\text { preventive measures }\end{array}$ & $1.39(1.12-1.72)$ & 0.002 & $1.23(1.02-1.47)$ & 0.03 & $1.10(0.88-1.37)$ & 0.41 \\
\hline $\begin{array}{l}\text { Perceived preparedness of medical system in } \\
\text { Karachi }\end{array}$ & $1.09(0.82-1.46)$ & 0.56 & $1.44(1.08-1.93)$ & 0.01 & $1.14(0.82-1.59)$ & 0.43 \\
\hline \multicolumn{7}{|l|}{ Social-structural level variable } \\
\hline $\begin{array}{l}\text { Number of preventive measures implemented } \\
\text { by the office }\end{array}$ & $1.26(1.13-1.39)$ & $<0.001$ & $1.20(1.09-1.31)$ & $<0.001$ & $1.08(0.97-1.20)$ & 0.16 \\
\hline
\end{tabular}

had reported 569,846 cases and 12,563 deaths. ${ }^{1}$ The lower COVID-19 burden in Pakistan could be the reason for not maintaining high compliance to PPMs. This deduction could also be supported by the finding that only 48 (11.7\%) employees considered themselves to be at a high risk of contracting the virus. Moreover, the fatalistic belief that if one is destined to contract COVID-19, it becomes unavoidable irrespective of the preventive measures taken also contributes to reduced compliance.

This study highlights issues that should be addressed through targeted interventions. Despite sufficient availability of face masks, $\sim 64.2 \%$ of the participants responded to have reused their facemasks. Efforts should be put in raising awareness regarding the proper handling and disposal of facemasks according to the guidelines set by the WHO. ${ }^{17}$ The reuse of surgical masks should be discouraged, and frequent washing of fabric masks should be encouraged.

According to the findings of the study, interventions should be designed according to the needs of various groups. Male workers were less likely to wear a face mask consistently in their offices compared with female workers. Decreased compliance of males to PPMs has also been reported in other studies. ${ }^{13,18,19}$ Efforts should be made to determine factors associated with decreased compliance by males, and they should be educated accordingly. Because the odds of sanitizing hands were higher for those who received tertiary education (college/university and postgraduate) compared with those who have only done intermediate or matriculation, more attention should be given to individuals with lower education levels. Health promoting messages should be designed according to the literacy rate of the employees so that they could be easily interpreted by them. Also, heads of organizations reported greater odds of avoiding crowds compared with those appointed at lower designations. This could be because higher ranks in the organizational hierarchy of an office come with added responsibility. To be role models to their subordinates, they displayed greater compliance to PPMs. Lower odds of sanitizing hands for the age group 18 to 25 could be due to the observation that the rate of hospitalization and death due to COVID-19 is lower for the age-group 18 to 29 compared with ages $\geq 30$. $^{20}$

The government of Pakistan issued guidelines regarding the mitigation of spread of person-to-person transmission of COVID-19 to allow safe resumption of work in offices. ${ }^{21}$ At the social-structural level, the preventive measures implemented by the offices played important roles in COVID-19 prevention, as the number of preventive measures implemented by the offices were associated with compliance with two of the personal preventive measures. Some of these measures directly increase access to face masks, such as provision of facemasks (75.9\%) and making them mandatory (81.5\%). Majority of employees (81.5\%) have also reported that measuring body temperature, and requiring hand sanitation upon entering the workplace is a mandatory practice in their workplace. These measures can directly increase compliance to PPMs. However, only $58.4 \%$ of the respondents reported that social distancing of 6 feet is practiced in their offices. This finding is troublesome as physical distancing has been strongly advocated by the WHO to control the spread of the virus. ${ }^{4}$ Hence, interventions such as spacing of desks should be made to maintain social distancing. Only $52.6 \%$ of the employees have reported that they are called on alternate days by their offices even though implementation of this measure could allow for physical distancing and limit interaction of workers in the workplace.

Perceived effectiveness of individual and governmental preventive measures had a strong influence on compliance with PPMs. The importance of believing that preventive measures would be effective has been highlighted in other studies as well. ${ }^{9,10}$ Thus, it shows that the campaigns have been effective in raising awareness among people regarding the efficacy of the PPMs in preventing COVID-19. Hence more efforts should be directed toward such campaigns.

This study has some limitations. First, the data were selfreported, and authentication was not feasible. Recall bias might have occurred. Participants may have also overreported their compliance with PPMs due to social desirability. 
Second, some behavioral factors that may influence personal preventive behaviors during the COVID-19 pandemic were not considered in this study, such as comfort of adopting these preventive measures or personal loss of a loved one due to the pandemic. Third, the study cannot be generalized to all the offices in Karachi because the sample size was limited. Also, the resource constraints of the offices in implementation of the measures was not considered. Lastly, compliance with PPMs despite having contracted COVID-19 has not been investigated in our study.

\section{CONCLUSION}

Gaps were observed in the implementation of all three personal preventive measures. Hence, efforts need to be made to ensure adherence to the guidelines advocated by the WHO for effective infection control in the workplace. Rigorous awareness campaigns need to be carried out at governmental and organizational level. The organization should ensure strict implementation of personal preventive measures by the employees. Factors that affect compliance should be investigated thoroughly. Through this, effective and targeted interventions can be devised at both the government and office levels, thus increasing compliance. Health messages should be designed according to the literacy rate of the employees so that it can be understood by majority of the population.

Received May 23, 2021. Accepted for publication September 9, 2021.

Published online October 4, 2021.

Acknowledgments: The American Society of Tropical Medicine and Hygiene has waived the Open Access fee for this article due to the ongoing COVID-19 pandemic and has assisted with publication expenses.

Authors' addresses: Pankaj Kumar, Aruba Sohail, Mir Umer Farooq Alam Shah, Maman Khurshid, and Farah Yasmin, Department of Internal Medicine, Dow Medical College, Dow University of Health Sciences, Karachi, Pakistan, E-mails: pankajkbutani@gmail.com, aruba.shl@gmail.com, umermir137@gmail.com, mamankhurshid00@ gmail.com, and farahyasmin972@yahoo.com. Muhammad Sohaib Asghar, Internal Medicine, Dow University Hospital-Ojha Campus, Karachi, Pakistan, E-mail: sohaib_asghar123@yahoo.com.

This is an open-access article distributed under the terms of the Creative Commons Attribution (CC-BY) License, which permits unrestricted use, distribution, and reproduction in any medium, provided the original author and source are credited.

\section{REFERENCES}

1. World Health Organization, 2020. Weekly epidemiological update. Geneva, Switzerland: WHO. Available at: https:// www.who.int/publications/m/item/weekly-epidemiologicalupdate-on-covid-19-29-june-2021. Accessed July 12, 2021.

2. Shezhad R, 2020. Govt to end lockdown from 9th in phases. The Express Tribune. Available at: https://tribune.com.pk/ story/2216236/1-lockdown-eased-phases-starting-may-9-pmimran. Accessed May 7, 2020.

3. World Health Organization, 2020. Coronavirus disease (COVID19): how is it transmitted? Available at: https://www.who.int/ emergencies/diseases/novel-coronavirus-2019/questionand-answers-hub/q-adetail/coronavirus-disease-covid-19how-is-it-transmitted. Assessed July 9, 2020

4. World Health Organization, 2020. Coronavirus disease (COVID19) advice for the public. Available at: https://www.who.int/ emergencies/diseases/novel-coronavirus-2019/advice-for-public. Accessed April 9, 2020.

5. Zhang $L$ et al., 2020. What is required to prevent a second major outbreak of SARS-CoV-2 upon lifting quarantine in Wuhan City, China. Innovation (NY) 1: 100006.

6. Chang SL, Harding N, Zachreson C, Cliff OM, Prokopenko M, 2020. Modelling transmission and control of the COVID-19 pandemic in Australia. Nat Commun 11: 5710.

7. Andarge $E$ et al., 2020. Intention and practice on personal preventive measures against the COVID-19 pandemic among adults with chronic conditions in southern Ethiopia: a survey using the theory of planned behavior. J Multidiscip Healthc 13: $1863-1877$.

8. Melki $\mathrm{J}$ et al., 2020. Media exposure and health behavior during pandemics: the mediating effect of perceived knowledge and fear on compliance with COVID-19 prevention measures. Health Commun. Available at: https://doi.org/10.1080/ 10410236.2020.1858564.

9. Clark C, Davila A, Regis M, Kraus S, 2020. Predictors of COVID19 voluntary compliance behaviors: an international investigation. Glob Transit 2: 76-82.

10. Seale $\mathrm{H}$ et al., 2020. COVID-19 is rapidly changing: examining public perceptions and behaviors in response to this evolving pandemic. PLoS One 15: e0235112.

11. Dean AG, Sullivan KM, Soe MM, 2013. OpenEpi: Open Source Epidemiologic Statistics for Public Health. Available at: http:// openepi.com/Menu/OE_Menu.htm.

12. World Health Organization, 2020. Survey tool and guidance rapid: simple, flexible behavioural insights on COVID-19. Geneva, Switzerland: WHO. Available at: https://www.euro. who.int/ data/assets/pdf file/0007/436705/COVID-19-surveytool-and-guidance.pdf. Accessed July 29, 2020.

13. Pan $Y$ et al., 2020. Self-reported compliance with personal preventive measures among chinese factory workers at the beginning of work resumption following the COVID-19 outbreak: cross-sectional survey study. J Med Internet Res 22: e22457.

14. World Health Organization, 2020. WHO director-general's opening remarks at the media briefing on COVID-19. Geneva, Switzerland: WHO. Available at: https://www.who.int/directorgeneral/speeches/detail/who-director-general-s-openingremarks-at-the-media-briefing-on-covid-19-11-march2020. Accessed March 11, 2020.

15. World Health Organization, 2021. WHO coronavirus (COVID-19) dashboard 2021. Geneva, Switzerland: WHO. Available at: https://covid19. who.int/?gclid=CjwKCAiA1eKBBhBZEiwAX3g ql6QI9oOljSp3D3eUoWnSwKRxHXFzROfMluS_Nka3kvDZUK RIEeeipRoCV6gQAvD_BwE. Accessed April 28, 2021.

16. Pakistan Government. Know about COVID-19, 2021. See the Realtime Pakistan and Worldwide COVID-19 Situation. Available at: https://covid.gov.pk/. Accessed February 24, 2021.

17. World Health Organization, 2020. Coronavirus disease (COVID-19) advice for the public: when and how to use masks. Available at: https://www.who.int/emergencies/ diseases/novelcoronavirus-2019/advice-for-public/when-andhow-to-use-masks. Accessed December 1, 2020.

18. Azene ZN et al., 2020. Adherence towards COVID-19 mitigation measures and its associated factors among Gondar City residents: a community-based cross-sectional study in northwest Ethiopia. PLoS One 15: e0244265.

19. Paul A et al., 2020. Knowledge, attitudes, and practices toward the novel coronavirus among Bangladeshis: implications for mitigation measures. PLoS One 15: e0238492.

20. Centers for Disease Control and Prevention, 2021. Risk for COVID-19 infection, hospitalization, and death by age group. Available at: https://www.cdc.gov/coronavirus/2019-ncov/ covid-data/investigationsdiscovery/hospitalization-deathby-age.html. Accessed February 18, 2021.

21. Pakistan Government, 2020. Guidelines for government employees and organizations in the wake of COVID-19 epidemic. Available at: https://storage.covid.gov.pk/new_guidelines/ 07June2020_20200607_Guidelines_for_Government_Em ployees_and_Organizations_3401.pdf. Accessed June 7, 2020. 